\title{
Ball in the Wall: Mesenteric Fibromatosis-a Rare Case Report
}

\section{Abhinav Deshpande ${ }^{1} \cdot$ Ankita Tamhane $^{1} \cdot$ Y. S. Deshpande ${ }^{2} \cdot$ Radhika Pagey $^{1} \cdot$ Meena Pangarkar $^{1}$}

Received: 16 July 2019 / Accepted: 1 April 2020 / Published online: 25 April 2020

(C) The Author(s) 2020

\begin{abstract}
Introduction Mesenteric fibromatosis-desmoid tumor of mesentery is a rare benign soft tissue tumor of mesentery. On CT, it mimics gastrointestinal stromal tumor (GIST).

Case Report A 44-year-old female with small intestinal mass, preoperatively diagnosed radiologically and pathologically as GIST. Conclusion Mesenteric fibromatosis is a rare tumor often mistaken for GIST. Histopathology and immunohistochemistry is the key as management of both the tumors differs.
\end{abstract}

Keywords Mesenteric fibromatosis · GIST · Desmoid tumor of mesentery

\section{Introduction}

Mesenteric fibromatosis, also known as desmoid tumor of mesentery is a rare benign soft tissue proliferative tumor having its origin in the mesenteric tissue. It is a locally aggressive tumor. Though it lacks malignant potential, recurrences have been documented in the literature. It is important to differentiate mesenteric fibromatosis from GIST (gastrointestinal stromal tumor) as it is its closest differential on radiology as well as on histopathology. The management of both tumors is completely different. Mesenteric fibromatosis is treated by surgical resection. $\mathrm{R} 0$ resection minimizes the chances of local recurrence. Treatment of GIST is surgery along with Tyrosine Kinase inhibitors. Misdiagnosis can lead to hazardous therapeutic management.

We report a case of 44-year-old female presenting with small intestinal tumor preoperatively suspected as GIST.

\section{Case Report}

A 44-year-old female presented to us with history of vague abdominal discomfort. She was previously operated for total

Ankita Tamhane

ankitatamhane9988@gmail.com

1 National Cancer Institute,Nagpur, 25, Outer Hingna Ring Road, Mouza-Jamtha, Nagpur, 441108, Maharashtra, India

2 Deshpande Nursing Home, Nagpur, India abdominal hysterectomy for multiple fibroids and was on regular follow up. On follow up ultrasonography, the radiologist reported small intestinal soft tissue lesion and histopathological correlation was suggested. Transabdominal CT-guided biopsy was done and was reported as benign spindle cell neoplasm suspicious of GIST and was advised for immunohistochemistry (IHC) for confirmation of diagnosis. However, patient being unaffordable IHC was not performed and the patient was directly referred to us. The CECT reported the same radiological finding as that of ultrasonography revealing small intestinal soft tissue mass, well-circumscribed homogenously hypoechoic measuring approximately $11 \times 7.5 \times 6 \mathrm{~cm}$ probably originating from intestinal wall suspicious of GIST(Figs. 1 and 2).

The patient underwent exploratory laparotomy. Intraoperatively to our surprise, there were multiple soft tissue masses, largest dumbbell-shaped mass measuring approximately $11 \times 7.5 \times 6 \mathrm{~cm}$ attached to the wall of small intestine and invading the surrounding mesentery. The tumor was close to the root of mesentery; however, no gross invasion was seen. Also, there were two small nodules similar in appearance at separate sites in the same intestinal segment. For attaining R0 resection, a large segment of small intestine had to be resected measuring approximately $60 \mathrm{~cm}$. Intraoperative and postoperative period was uneventful, and the specimen was sent for histopathological examination.

On gross examination the intestinal segment measured approximately $60 \mathrm{~cm}$ in length, with a dumbbell-shaped tumor measuring approximately $11 \times 7.5 \times 6 \mathrm{~cm}$ arising from the intestinal wall and extending deep into the surrounding mesentery (Fig. 3). Another 2 smaller lesions were also identified largest measuring $1.5 \times 1 \times 1 \mathrm{~cm}$ embedded in the mesenteric 


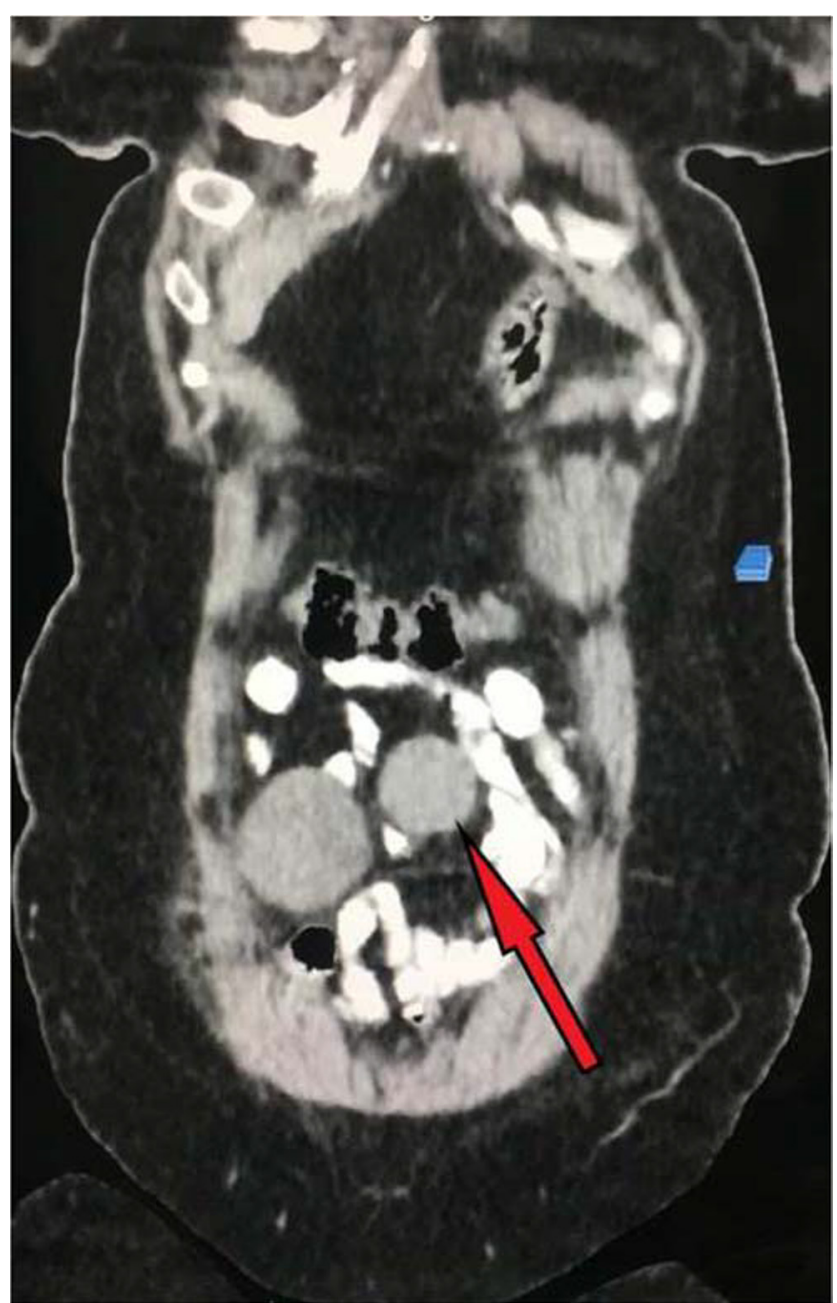

Fig. 1 CT scan image shows a dumbbell-shaped tumor (marked by red arrow) attached to the small intestine

tissue. The proximal resection margin was $14 \mathrm{~cm}$ away from the main tumor, and distal resection margin was $30 \mathrm{~cm}$ away from the main tumor. However, two smaller nodules closest being $8 \mathrm{~cm}$ from the distal resection margin were identified which were not reported on pre-operative CT. The two smaller nodules were approximately $20 \mathrm{~cm}$ away from the main tumor.

The tumor was well circumscribed, and the cut surface showed a solid, homogenous mass with whirling pattern without areas of hemorrhage or necrosis. Representative sections were taken for histopathological diagnosis.

On microscopy, the sections showed well-circumscribed benign spindle cell tumor arising from the serosa with cytologically bland spindle cells, stellate-shaped cells forming fascicles and storiform pattern. Prominent sclerosed blood vessels were seen with collagenized fibers. Intestinal mucosa, submucosa, muscularis propria, and subserosal fat were unremarkable (Figs. 4 and 5).

For confirmation of diagnosis, IHC was performed which showed immunoreactivity for nuclear beta catenin, vimentin, and variable SMA positivity while tumor cells were negative for CD-117, DOG-1,CD-34, and ALK-1 ruling out the differentials of GIST and inflammatory myofibroblastic tumor (IMFT). MIB 1 labeling index was $1 \%$.

Follow up Immediately after 2 months of surgery, the patient presented with diarrhea because of short bowel syndrome and was managed symptomatically. The patient is post 1 year of surgery and on regular follow up with the operating surgeon and presently asymptomatic.

The patient underwent colonoscopy for evaluation of familial adenomatous polyposis (FAP); however, it was unremarkable.

\section{Discussion}

Mesenteric fibromatosis is a benign tumor arising from the fibroblasts of mesentery. It is postulated that its occurrence may be due to previous surgical trauma, handling of the intestine and also is often related to hormonal influence. Familial
Fig. 2 CT scan sagittal section image shows a dumbbell-shaped tumor (marked by red arrow) attached to the small intestine

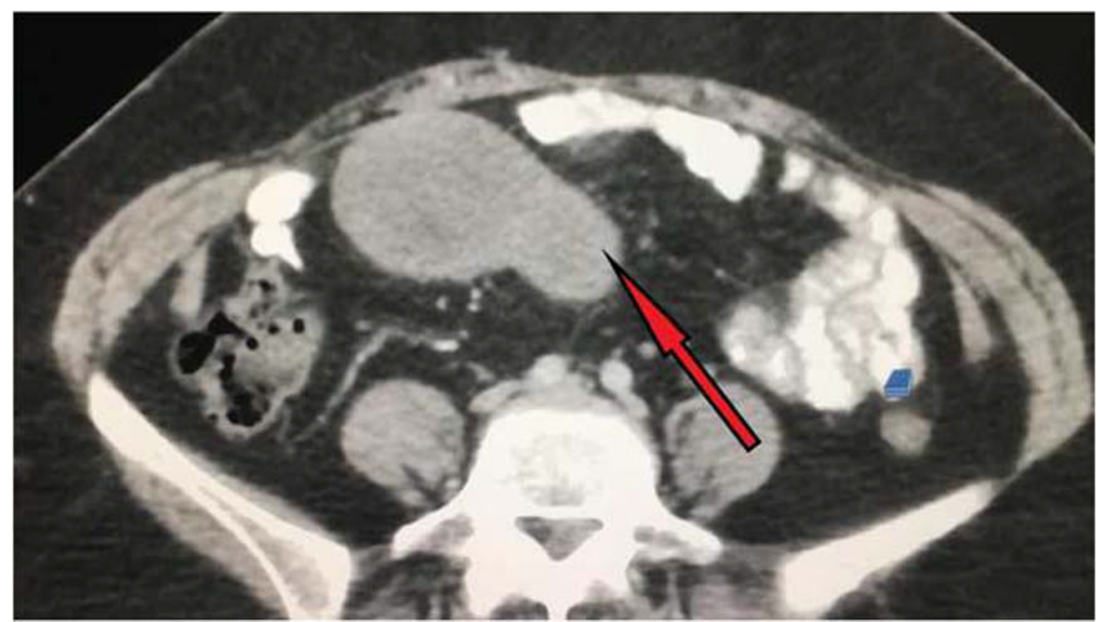


Fig. 3 Gross of the resected specimen showing a dumbbellshaped tumor, cut section solid white whirling seen. A smaller tumor marked by red circle is seen separately

Fig. 4 Microscopy $(\times 10)$ shows a spindle-shaped neoplasm arising from serosa. Muscularis propria and subserosa is unremarkable
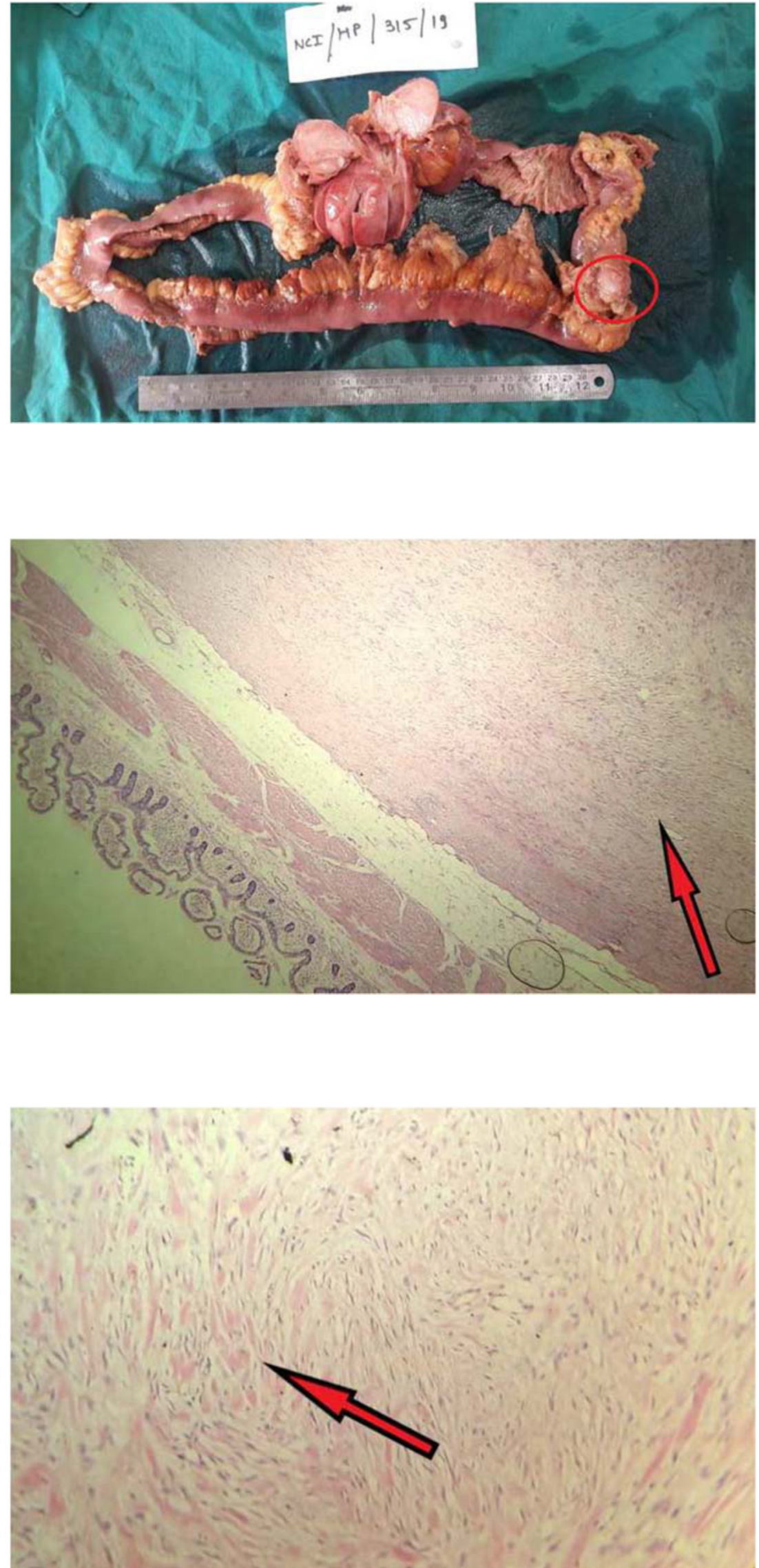

Fig. 5 Microscopy $(\times 40)$ shows spindle cells arranged in whorls and storiform pattern.

Collagenized fibers are also seen. Mitosis is not seen 


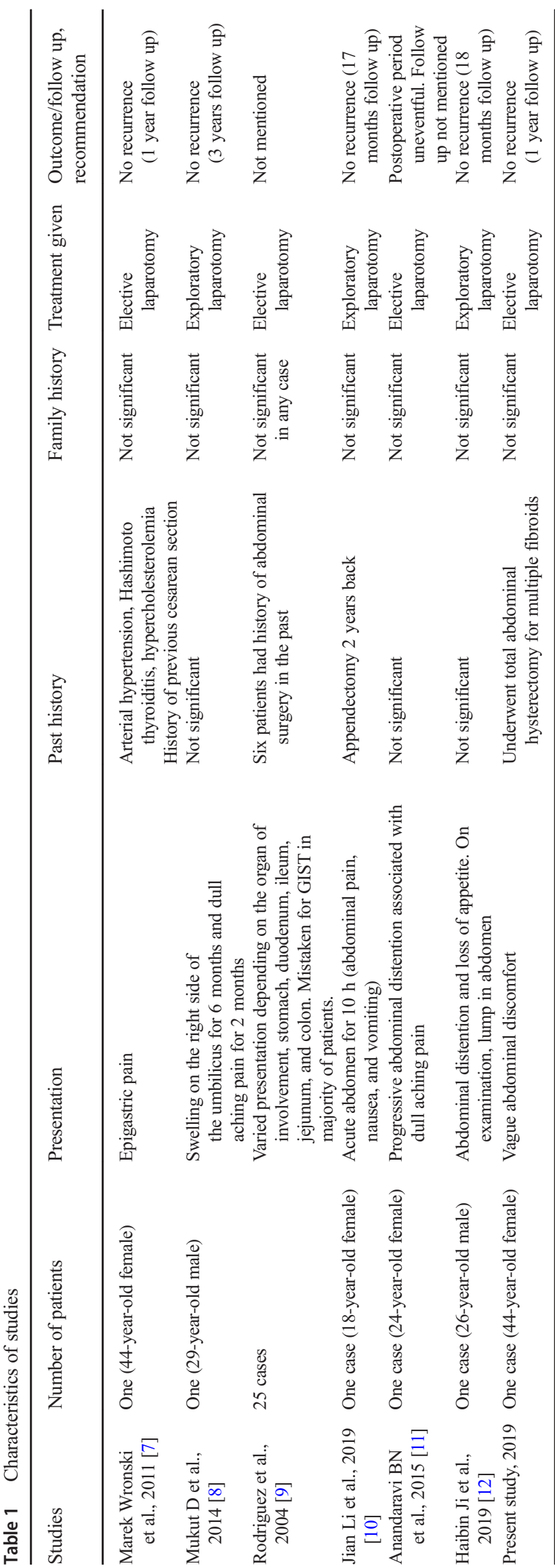

adenomatous polyposis (FAP) and Gardner syndrome patients are often at risk of developing mesenteric fibromatosis.

Approximately $10 \%$ of patients develop mesenteric desmoids. FAP-associated fibromatosis have an aggressive clinical course with increased rate of recurrences. APC (adenomatous polyposis coli) gene mutations in FAP lead to overexpression of nuclear beta catenin [1-4].

Clinical course of mesenteric fibromatosis is usually uneventful after surgical resection. Rate of recurrence in sporadic cases is very low.

However, large tumors not resected for long can often cause intestinal obstruction or can lead to mesenteric ischemia. Treatment modality of mesenteric desmoids is individualized, with surgical resection done only in wellcircumscribed tumors and tumors which do not invade the root of mesentery. Fifty-three to $67 \%$ of mesenteric desmoids are resectable [5].

Radiation and chemotherapy is not found useful in cases of R0 resection and patients with sporadic desmoids. Doxorubicin is given in cases of recurrent tumors and tumors with genetic mutation. Tumors which are resistant to doxorubicin have been tried with imatinib, which is most commonly useful in cases of GIST; however, its utility has not been proven in large studies (Table 1) [6].

\section{Conclusion}

The present case report documents an unusual case of mesenteric fibromatosis.

IHC-proven histopathological diagnosis is mandatory for mesenteric fibromatosis as other closest differentials have a completely different surgical and therapeutic management. MRI is a preferred modality of diagnosis than CT. Usually, mesenteric fibromatosis is diagnosed as GIST on radiology and tissue diagnosis followed by IHC is mandatory.

$\mathrm{R} 0$ resection is vital to prevent recurrences.

Open Access This article is licensed under a Creative Commons Attribution 4.0 International License, which permits use, sharing, adaptation, distribution and reproduction in any medium or format, as long as you give appropriate credit to the original author(s) and the source, provide a link to the Creative Commons licence, and indicate if changes were made. The images or other third party material in this article are included in the article's Creative Commons licence, unless indicated otherwise in a credit line to the material. If material is not included in the article's Creative Commons licence and your intended use is not permitted by statutory regulation or exceeds the permitted use, you will need to obtain permission directly from the copyright holder. To view a copy of this licence, visit http://creativecommons.org/licenses/by/4.0/. 


\section{References}

1. Zhou YL, Boardman LA, Miller RC (2010) Genetic testing for young-onset colorectal cancer: case report and evidence-based clinical guidelines. Radiol Oncol 44:57-61

2. Gurbuz AK, Giardiello FM, Petersen GM, Krush AJ, Offerhaus GJ, Booker SV, Kerr MC, Hamilton SR (1994) Desmoid tumours in familial adenomatous polyposis. Gut 35:377-381

3. Bridge JA, Sreekantaiah C, Mouron B, Neff JR, Sandberg AA, Wolman SR (1992) Clonal chromosomal abnormalities in desmoid tumors. Implications for histopathogenesis. Cancer 69:430-436

4. Alman BA, Li C, Pajerski ME, Diaz-Cano S, Wolfe HJ (1997) Increased beta-catenin protein and somatic APC mutations in sporadic aggressive fibromatoses (desmoid tumors). Am J Pathol 151: 329-334

5. Smith AJ, Lewis JJ, Merchant NB, Leung DH, Woodruff JM, Brennan MF (2000) Surgical management of intra-abdominal desmoid tumours. Br J Surg 87:608-613

6. Chu Y, Guo Q, Wu D (2017) Mesenteric fibromatosis after resection for gastrointestinal stromal tumor of stomach. Medicine (Baltimore) 96(48):e8792
7. Wronski M, Ziarkiewicz-Wroblewska B, Slodkowski M, Cebulski W, Gornicka B, Krasnodebski IW (2011) Mesentric fibromatosis with intestinal involvement mimicking a gastro intestinal stromal tumor. Radiol Oncol 45(1):59-63

8. Mukut D et al (2014) Mesentric fibromatosis (desmoid tumor)- a rare case report. J Clin Diagn Res 8(11):ND01-ND02

9. Rodriguez et al (2004) Mesenteric fibromatosis with involvement of the gastrointestinal tract. A GIST simulator: a study of 25 cases. Am J Clin Pathol 121:93-98

10. Li et al (2019) Rare acute abdominal condition caused by mesenteric fibromatosis perforation- a case report. Medicine 98:2

11. Anandaravi BN et al (2015) Giant aggressive Mesentric Fibromatosis- a case report. J Clin Diagn Res 9(2):PD07-PD08

12. Ji et al (2019) Jiant mesenteric fibromatosis involving the muscular layer of the colon. Medicine 98:1

Publisher's Note Springer Nature remains neutral with regard to jurisdictional claims in published maps and institutional affiliations. 